\section{Engage the public to stop bear trafficking}

Last month, authorities in China confiscated 100 kilograms of bear paws. Many of the animals had been massacred in Russia, then the paws smuggled into China. Neither country is managing to control this monstrous trade.

Bear paws are a coveted delicacy in China, fetching up to ten times the price that they do in Russia. This is despite some species having a second-class protected status under Chinese law, with bear hunting and the sale and eating of bear products strictly prohibited in the country.

The Chinese government must intensify its efforts against wildlife trafficking. Extensive publicity and public education will be the most effective way to kill demand for wildlife delicacies.

Zhengrong Yuan, Yingying

Han, Qiang Weng Beijing

Forestry University, China

qiangweng@bjfu.edu.cn

\section{China Nobel stirs up attack on academies}

The first Nobel prize to be awarded to a researcher in China has sparked heated debate in the country (see Nature 526, 174-175; 2015). This centres on the public's longterm dissatisfaction with the Chinese academy system, which consistently failed to recognize the scientific talent and originality of the prizewinner Youyou Tu.

Chinese news reports about Tu's award on 5 October drew attention to her 'three-no' status (that is, no overseas experience, no doctorate, no admission to a national academy - a status known as yuanshi). Citizens are indignant that her yuanshi application was repeatedly declined, despite her recommendation by the minister of health and her acclaim by international scientific bodies.

The unfairness of the yuanshi selection process is widely blamed on cronyism, nepotism and excessive bureaucracy (see, for example, C. Cao et al. Science 341, 460-462; 2013). China's academic institutions need to reform their moribund practices rapidly or they are likely to overlook other striking individuals and key grass-roots research in the future. Xin Miao Harbin Institute of Technology, Harbin, China. xin.miao@aliyun.com

\section{Badger-cull targets unlikely to reduce TB}

Two months ago, the government-advice body Natural England approved further licensed badger culls in parts of the United Kingdom in 2015. The aim is to reduce local badger densities by at least $70 \%$ to prevent the spread of tuberculosis (TB) to cattle (see go.nature. com/iiutvj). On the basis of the government's badger-population estimates, we calculate that these culls are unlikely to achieve the necessary reduction.

The latest minimum cull numbers derive from the lower $95 \%$ confidence bounds on population size estimates. For example, licensees in Dorset are required to kill at least 615 badgers in a population estimated at 879-1,547 animals (95\% confidence interval). Killing this number would give an estimated population reduction of between $39.8 \%$ and $70 \%$ (95\% confidence interval).

Equivalent confidence intervals for the 2015 (third annual) Somerset and Gloucestershire culls are, respectively, 50.8-70\% and $54-70 \%$ relative to the baseline population estimates. It is therefore unlikely that a $70 \%$ or greater reduction can be attained by these minimum cull numbers, assuming that the population estimates are accurate.

Evidence from a randomized controlled trial shows that better prospects for the control of cattle TB are offered by badger populations that are either reduced by more than $70 \%$ or left undisturbed - and potentially vaccinated (C. A. Donnelly et al. Nature 439, 843-846; 2006). The choice depends on a range of epidemiological, economic, social and ecological factors.

Christl A. Donnelly Imperial

College London, UK.

Rosie Woodroffe Institute of

Zoology, London, UK.

c.donnelly@imperial.ac.uk

Competing financial interests

declared; see go.nature.com/so3gvl.

\section{EU report advises on contentious research}

The United States has a de facto moratorium on genetic gain-offunction experiments that could increase the transmissibility or pathogenicity of potentially pandemic agents such as the H5N1 avian influenza virus. In Europe, opinion among scientists is divided on the benefits and risks of such research for policymakers. A new report on these differences by the European Academies Science Advisory Council (EASAC; see go.nature. $\mathrm{com} / \mathrm{jcdy} 2 \mathrm{w}$ ) will help to inform scientists and the public on this globally controversial research.

As well as risk-benefit assessment, the report addresses concerns such as scientific responsibility, research review and management systems, options for national and international biosafety and biosecurity advisory bodies, and the publication of sensitive information. It also highlights areas in which European Union regulations and best-practice guidelines need further consideration, notably those affecting the publication and export of research findings. We recommend an integrated approach to biorisk assessment and management, with responsibilities and action shared among researchers, institutions and funders.

Robin Fears, Volker ter Meulen EASAC, German National Academy of Sciences Leopoldina, Halle, Germany.

volker.termeulen@mail.uniwuerzburg.de

\section{Make raw emissions data public in China}

China's carbon emissions need to be estimated more accurately if the country is to meet its climate targets and participate in a nationwide emissionstrading scheme after 2017 (see F. Teng Nature 525, 455; 2015). Accounting errors will prevail until the nation's data sources are made transparent, measurable and verifiable.

For example, Teng points to discrepancies between our estimations of coal emissions (Z. Liu et al. Nature 524, 335-338; 2015) and those calculated by the government's data agencies - from information that is not publicly available. The comparison is invalid, however. Our estimates are derived from energy consumption and measured emission factors for coal acquired from 4,845 mines, rather than from final energy consumption and estimated emission factors averaged over all coal types.

Emissions estimates are even more uncertain in economies such as India, Indonesia and South Africa. China’s latest investment of 20 billion yuan (US $\$ 3.1$ billion) for climatechange mitigation and adaptation in developing countries could help these nations to compile measurable, accurate and accessible carbon emissions data. Dabo Guan University of East Anglia, Norwich, UK. Zhu Liu Harvard University, Cambridge, Massachusetts, USA. Wei Wei Shanghai Advanced Research Institute, Chinese Academy of Sciences, Shanghai, China. dabo.guan@uea.ac.uk

\section{CORRECTION}

An editing error in the

Correspondence by A. C. Lewis et al. (Nature 526, 195; 2015) attributed 29,000 UK deaths to particulate matter from diesel, rather than from all sources. 